\title{
Simulation Study on Gas Migration Law in Goaf Based on Fluent
}

\author{
REN Yu-hui \\ College of Mining and Coal, Inner Mongolia University of Science and Technology, 014010, China \\ nmrenyuhui@yeah.net
}

Keywords: gas migration, similar simulation, numerical simulation

Abstract. In this paper, the physical similarity theory and simulation method is based, through a coal mined zones similar simulation experiments obtained goaf under varying ventilation rate and different experimental conditions of high temperature and closed and so the distribution of methane concentration, and its detailed analysis, whereby the gas migration law in goaf. Using FLUENT software simulation on gas migration law in goaf bench prototype is simulated by a similar experiment and numerical simulation shows that, when taken out area ventilation is constant, upward along with the deepening of goaf gas concentration is increasing along side the tendency of the gas concentration increases from the inlet side to the return air by gas floating up the role at the height of the upper part of the gas concentration mining empty area at the bottom of the gas concentration is higher than the empty area

\section{Introduction}

Coal mine gas disaster become a major disaster, the gas disaster prevention has always been the most important task of Coal Mine Safety. Face Gas emission consists mainly of coal wall, falling coal and mined-out area into three parts, and the gob gas emission accounted for a large proportion of Gas Emission in Faces. The majority of mechanized mining face long wall mining face, and general gas long wall mining goaf Emission Face occupy more than the total amount of gas emission by $30 \%$ to $40 \%$, some even reach $70 \%$ to $80 \%$. A large number of gob gas emissions, often leading to Face Gas overrun and forced to stop production, and some may also cause a major accident, causing casualties and property losses. This paper based on the current domestic and foreign experts and scholars research on gas migration law in goaf using gas migration law experiment and numerical simulation of a combination of methods gob gas concentration on the dynamic changes of the analysis, resulting in migration law in goaf of methane. Research on this subject can reduce disaster losses, to be gob gas-based governance is important.

\section{Theoretical model}

Gas flow in goaf of differential equations more, molecular diffusion and mechanical dispersion is mined-out area of methane two diffusion process. Effect due to molecular diffusion is small, so a major role in the process of mechanical dispersion of gas diffusion in the mined-out area. The law of conservation of mass and dispersed to obtain methane gas power according to the hydrodynamic dispersion equation as follows:

$$
\frac{\partial C}{\partial t}=\frac{\partial}{\partial_{x_{i}}}\left[D i_{j} \frac{\partial C}{\partial x_{i}}\right]-\frac{\partial}{\partial_{x_{i}}}\left(C u_{i}\right)+I_{C H_{4}}
$$

Where $\mathrm{C}$ is the concentration of methane in the mined-out area, $\mathrm{g} / \mathrm{m}^{3} ; \mathrm{D}_{\mathrm{ij}}$ for the nine component dynamic dispersion coefficient $\mathrm{m}^{2} / \mathrm{s} ; \mathrm{u}_{\mathrm{i}}$ is the average velocity vector components, $\mathrm{m} / \mathrm{s}$; gas concentration distribution at steady state when the laws of gas diffusion differential equation is:

$$
\frac{\partial}{\partial_{x_{i}}}\left[D i_{j} \frac{\partial C}{\partial x_{i}}\right]-\frac{\partial}{\partial_{x_{i}}}\left(C u_{i}\right)+I_{C_{4}}=0
$$

The mined-out area considered non-uniform porosity porous media. Gas Mined areas are mainly coal and residual coal gas methane wall in two parts. They in two ways (adsorption, free) exist, due to 
the wind pressure ventilation pressure, atmospheric pressure, its own buoyancy, wind and other factors produced by regular transport and poor concentration. Wherein the ventilation pressure, the amount of gas emission size and fluid viscous resistance of gas transport processes play a major role. Mined areas into the most romantic Face came back after back romantic in a small part in the mined-out area formed goaf leakage air flow, so the gas flow is mainly diffusion motion and linear motion penetration two species.

\section{Method of gas migration law Simulation}

To build three-dimensional gob gas migration bench, using three-dimensional gob gas migration bench for gas migration law in goaf simulation experiments. Bench system development requirements based functions, the establishment of a bench box as the main framework for peristaltic pump flow controlled ventilation system, methane gas injection system, temperature control system and gas concentration test systems meet the test requirements of the comprehensive test station. Bench cabinet mainly by the angle, low carbon steel plate welded into its basic skeleton, on the basis of the basic skeleton, all around four sides bolted together. In order to facilitate removal and filling similar materials, each of the front and rear using two low carbon steel plate splicing.

For the realistic simulation of Gob process, added a U-shaped ventilation systems in the model. The system is managed by the recent U-ventilation, WG600S speed peristaltic pump, pressure meter, MF5700 (0-25L / min) gas mass flow meter components. Since the original bench can simulate Face $120 \mathrm{~m}$, which is U-shaped vent line can not meet the existing experiments, in order to broaden the face, in the original basis of ventilation pipe will be U-shaped tube has been transformed, as shown by the recent special $U$ type ventilation pipes, three-dimensional realization bench to seal coal Face ventilation, piping near the working face two dozen have sieve test, analog to Gob.

Table 1: Some material consumption

\begin{tabular}{|c|c|c|c|}
\hline Material & sand $(\mathrm{kg})$ & gypsum $(\mathrm{kg})$ & White powder $(\mathrm{kg})$ \\
\hline weight & 184 & 13.15 & 13.15 \\
\hline
\end{tabular}

Gas injection system simulation can mainly affect gas emission source. The system provides a test-bed model gas sources, mainly by helium gas cylinders, valves, balance tanks, gas pressure gauges, filters, flow control valves, MF5700 gas mass flow meter (0-10L / min), the shunt valve groups and pipeline components. Decompression valve from the cylinder out of the gas through, and then flow through the valve regulating the flow through the shunt valve shunt after implantation model mining model from the bottom bars. Gob Gas Emission source for the sub-emission, ie various gas sources are likely to release gas to the mined-out area, and finally due to the characteristics of mined-out area, the nature of the gas itself to achieve a balance. In order to maximize the gas injected into the model and the actual system do similar, we will split the gas introduction pipe mining bars, on the surface of the steel strip uniformly dense arrangement of $2 \mathrm{~mm}$ holes, so that the dissipation of the gas to be uniformly Mining empty region of space.

Ignore stress and rock strength, porosity and permeability only consider the different regions of the mined-out area, so selecting different sizes of sand, laying crushed coal as the main ingredient. Based on the horizontal, vertical, three-zone structure with the mined-out area is divided into three caving zone, fractured zone and bend with sink, turn on the caving zone along goaf accumulation zone to be divided into natural, load-affected zone and compaction stable area. Because they can not directly use material laying at the crack separation, so only consider the fractured porosity of less than caving zone, with a particle size of less than coal and crushed stone laying caving zone fracture zone, due to the bending sink with little presence or absence cracks and elimination, bending it did not sink with a paving material and mining parts of the same. 


\section{Gas migration law in goaf}

Select adopt the same discharge point blank area of the three experiments comparing the distribution of methane concentration in goaf in Figure 1. As is evident from Figure 1, when the gas release time is too short (10min, 30min), along goaf gas concentration gradient towards the large, deep low goaf gas concentration. With the increase of the gas release time, when release time of $180 \mathrm{~min}$, the mined-out area of methane concentration was significantly increased, the gas can diffuse permeates the entire gob gas at this time Mined areas basically balanced, so choose the gas release time At least 180min subsequent experiments.

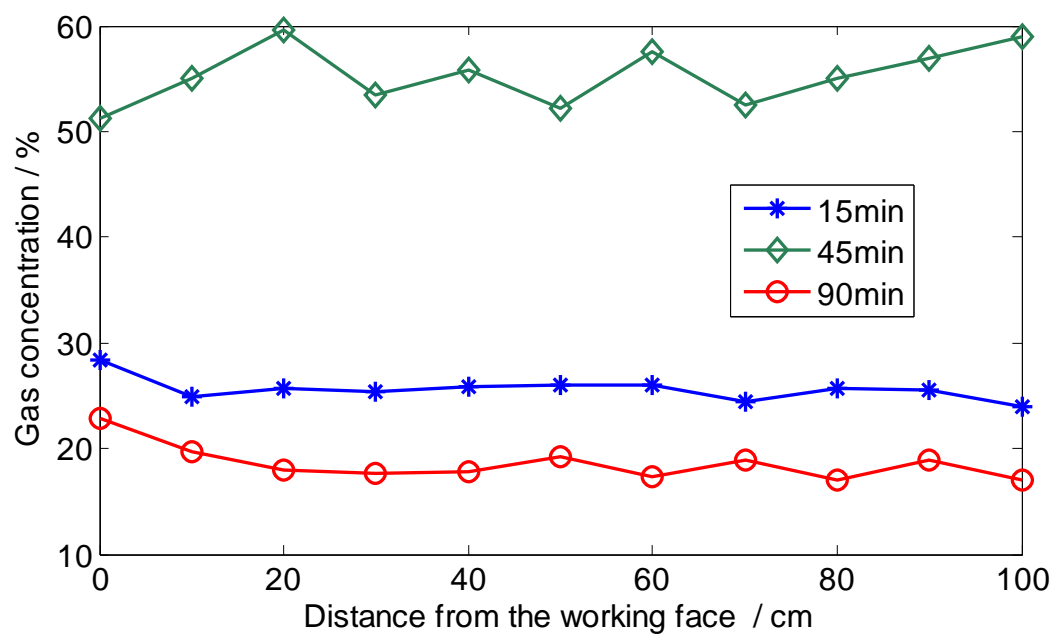

Figure 1: Ventilation time when gob gas concentration comparison

In the experimental station were verified after the experiment, has been released from a gas reference time 180min, while verification experiment also proved that a good seal bench, laid the foundation for the accuracy of subsequent experiments. The fourth set of experiments in order to get a certain amount of ventilation in the case of methane migration law in goaf. Figure 2 is a mined-out area of the ventilation rate $16 \mathrm{~L} / \mathrm{min}$, the gas release rate of $0.1 \mathrm{~L} / \mathrm{min}$, releasing the pressure $0.1 \mathrm{MPa}$, the release time $180 \mathrm{~min}$ gas Gob zone temperature at $20^{\circ} \mathrm{C}$ obtained along strike, dip and height on concentration profile.

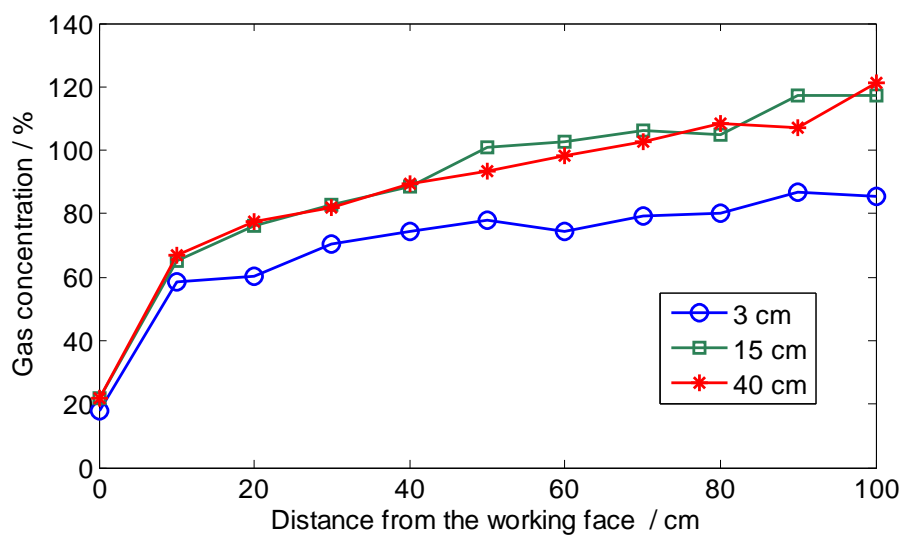

Figure 2: Ventilation rate is fixed along strike of gas concentration distribution

When normal ventilation, along mining strike on an empty area, gas concentration gradually increases from shallow to deep, shallow near goaf gas concentration changed slightly, but large empty area near the mining of deep changes in the magnitude of the gas concentration. The main reason for this distribution is in normal ventilation, close working surface mined area, its large void space, the porosity is large, it will lead to leakage from the face into the mined-out area of the diluted shallow goaf of methane, the gas concentration is relatively low. With the mined-out area in depth, porosity continuously smaller void space is severely compressed and far away from the working face, from the 
face romantic air leakage into the mining area is difficult to access to this area, so the gas concentration gradually increased, and stabilized.

\section{Conclusion}

When the ventilation is constant, along goaf direction, mined-out area near the working face area, by the influence of leakage air flow into the wind, Lane, gas concentration goaf shallow portion of the upward trend lower and moderate; away from face Central region mined-out area, although the inlet side of the gas concentration is low, but because the gas is not easily leak out romantic lead gas concentration increased rapidly; deep, gas concentrations continue to increase in the mined-out area, and stabilized. On along goaf tendency in recent Mining Area affected leak romantic, inlet side of the gas concentration is lower than the return air side of the gas concentration; away from the face area, reducing leakage by the romantic influence, this distribution Features waning. Mining empty area along the height of the influence of gas floating up the role of gas concentration is higher than the upper goaf goaf of mining the bottom of the gas concentration. Changing wind will affect the concentration distribution of methane in the mined-out area, when increasing the amount of wind; will reduce the gas concentration shallow goaf, and the leakage flow of goaf in deep stretch. Increasing the ventilation rate of return air intake on both sides so that the concentration difference increases, when the wind increased to a certain value, can affect the airflow to the upper mined-out area, causing lower the upper gob gas concentrations.

\section{Acknowledgements}

The authors thank the following items Buffet: Inner Mongolia University of Science and Technology Innovation Fund (2014QDL035)

\section{Reference}

[1] Zhu Hongqing, Liu Xingkui. Theoretical investigation on the relationship between tail roadway methane drainage and distribution of easily spontaneous combustible region in gob, Safety Science, Vol.50 (2012), p.618-623

[2] Zongyi Qin, Liang Yuan, Hua Guo, Qingdong Qu. Investigation of longwall goaf gas flows and borehole drainage performance by CFD simulation, International Journal of Coal Geology, Vol.150-151 (2015), p.51-63

[3] Hua Guo, Liang Yuan, Baotang Shen, Qingdong Qu, Junhua Xue. Mining-induced strata stress changes, fractures and gas flow dynamics in multi-seam longwall mining, International Journal of Rock Mechanics and Mining Sciences, Vol.54 (2012), p.129-139

[4] M. Politano, A. Arenas Amado, S. Bickford, J. Murauskas, D. Hay. Evaluation of operational strategies to minimize gas supersaturation downstream of a dam, Computers \& Fluids, Vol.68 (2012), p.168-185

[5] R. Gupta, M.D. Kaulaskar, V. Kumar, R. Sripriya, B.C. Meikap, S. Chakraborty. Studies on the understanding mechanism of air core and vortex formation in a hydrocyclone, Chemical Engineering Journal, Vol.144 (2008), p.153-166

[6] Jae Hyuk Jo, Woo Tae Kim. Numerical simulation of water droplet dynamics in a right angle gas channel of a polymer electrolyte membrane fuel cell, International Journal of Hydrogen Energy, Vol.40 (2015), p.8368-8383

[7] Anh Dinh Le, Biao Zhou. A general model of proton exchange membrane fuel cell, Journal of Power Sources, Vol. 182 (2008), p.197-222 